\title{
Laboratory tests on arsenic leaching from excavated shale rock by elevated temperatures
}

\author{
Atsushi Takai ${ }^{1, *}$, Yusuke Iwata $^{1}$, Lincoln W. Gathuka ${ }^{1}$, and Takeshi Katsumi ${ }^{1}$ \\ ${ }^{1}$ Kyoto University, Graduate School of Global Environmental Studies, Kyoto, Japan
}

\begin{abstract}
This manuscript focuses on the leaching of geogenic arsenic (As) from shale rock at different temperatures. In Japan, the utilisation of geogenic contaminated soils and rocks for construction such as in embankment is much encouraged. Therefore, when applying thermally active geo-systems such as thermal energy storage and ground-source heat pump, which are associated with ground temperature changes, we need to know its impact on the leaching behaviour of such contaminated geomaterials. In this study, the leaching of chemicals from an excavated shale rock containing geogenic As was assessed using a shaking and non-shaking batch test. In those experiments, different temperatures up to $40{ }^{\circ} \mathrm{C}$ and contact times ranging from 6-360 h were employed. Overall, it was found out that more As was leached with elevated temperatures and its concentration was notably higher under the non-shaking condition. Further, under the non-shaking condition, its concentration was highest at $40{ }^{\circ} \mathrm{C}$ with contact time of $360 \mathrm{~h}$, whereby ca. 0.06 $\mathrm{mg} / \mathrm{L}$ As was leached, which is 6 times the permissible limit of $0.01 \mathrm{mg} / \mathrm{L}$ in Japan.
\end{abstract}

\section{Introduction}

In Japan, soils and rocks excavated at construction sites are frequently reported to be contaminated with geogenic heavy metals and metalloids (hereon heavy metals) such as arsenic (As), fluorine (F), lead (Pb), etc.; in relatively low concentrations, due to their geologic histories [1]. Leaching of these constituents in concentrations higher than the permissible limits regulated under the Japanese Soil Contamination Countermeasures Law (SCCL) often occurs due to contact with water and/or air [2].

To elucidate the metal leaching concentrations of such contaminated materials, several kinds of batch leaching tests are widely used, for example, the Japanese Notification No. 46, which is the Japanese standard way. However, the applicability of the findings in the field remains to be a challenge, because they do not fully simulate the field conditions of soil and groundwater [3], nor account for the ground temperature changes caused by the fluctuations in the daily and seasonal temperature, which are observed in shallow ground $[4,5]$ or in an embankment [6], as shown in Fig. 1, where the soils and rocks contaminated with geogenic heavy metals are utilised [7]. Moreover, in recent years, there has been active research on various geotechnical and geoenvironmental systems such as underground thermal energy storage and energy piles which involve changes in the ground temperature $[8,9]$. Consequently, the temperature effects on the behaviour of geostructures need to be clarified also from the geoenvironmental perspectives since the environmental impacts of such contaminated soils and rocks can be changed from thermo-mechanical-chemical interactions.

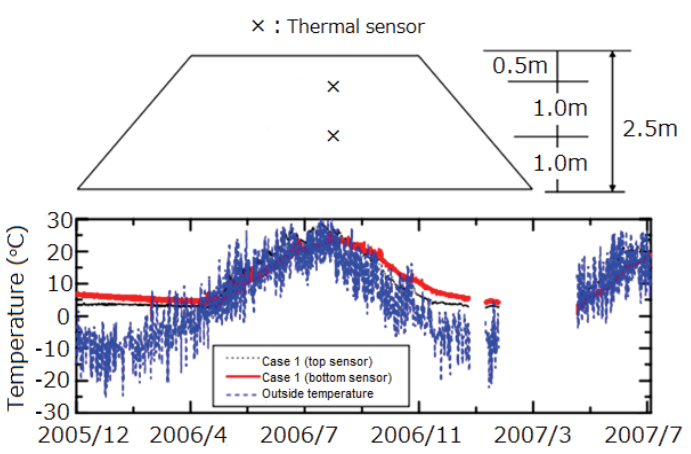

Fig. 1. Profiles of temperature inside and outside embankment (edited from Tamoto et al., 2008).

Arsenic is the most frequently-reported geogenic element contained in the soils and rocks excavated at construction sites in Japan. Takai et al. [10] investigated the As leaching of mudstone with a total As content of $27 \mathrm{mg} / \mathrm{kg}$ under different temperatures. The authors found out that under a non-shaking condition, a higher temperature and/or a longer contact time can increase the leaching concentrations of As. However, since the characteristics such as friability and chemical composition should vary with rock type, further knowledge of the temperature effects on the leaching behaviour is required. In this study, shaking and nonshaking batch leaching tests were carried out on a crushed shale rock that was excavated at a shieldtunneling project in Japan. Several temperatures that are expected in the field ranging from $5-60{ }^{\circ} \mathrm{C}$ were considered. Further, to evaluate the time dependency of

\footnotetext{
* Corresponding author: takai.atsushi.2s@kyoto-u.ac.jp
} 
the leaching behaviour of As, those experiments were conducted using different contact times up to $360 \mathrm{~h}$.

\section{Materials and methodologies}

\subsection{Materials}

Shale rock, which was excavated in a shield-tunneling project in Japan, was used after crushing it with a jaw crusher to pass through a $2 \mathrm{~mm}$-opening screen. Figure 2 shows the appearance of the crushed rock. Its particle density of $2.73 \mathrm{~g} / \mathrm{cm}^{3}$ was determined as per JIS A 1202:2009; particle size distribution, shown in Fig. 3, as per JIS A 1204:2009. According to the "Method of Classification of Geomaterials" guidelines developed by the Japanese Geotechnical Society (JGS), this crushed rock corresponded to sand (S).

For the chemical analysis, the sample was manually ground to $<75 \mu \mathrm{m}$ using an agate mortar and pestle and then analysed by X-ray fluorescence (XRF) (EDX-720, Shimadzu). Its chemical composition is summarised in Table 1. It has an As content of $20 \mathrm{mg} / \mathrm{kg}$ which is well within the $1-20 \mathrm{mg} / \mathrm{kg}$ values reported for soils formed from igneous and sedimentary rocks [11].

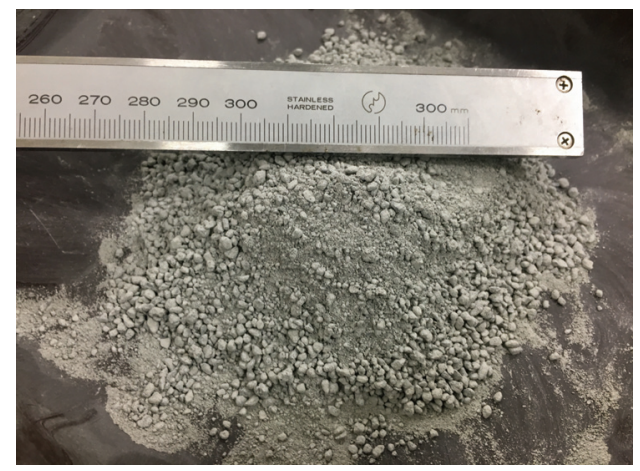

Fig. 2. Appearance of crushed shale rock.

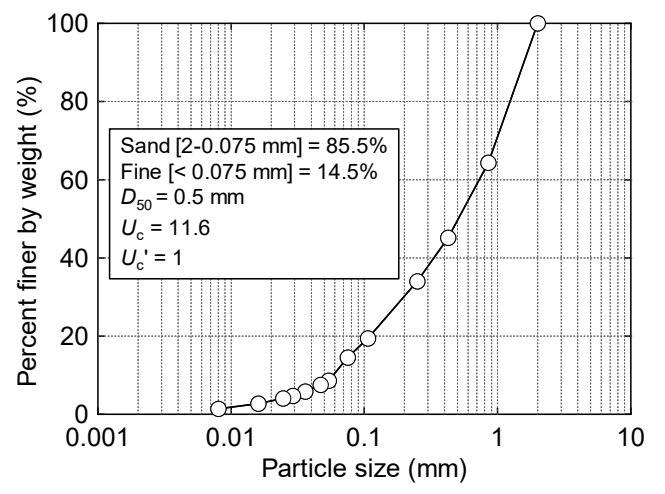

Fig. 3. Particle size distribution of crushed shale rock.

Table 1. Chemical analysis results of the shale rock (unit: \%).

\begin{tabular}{llllll}
\hline $\mathrm{SiO}_{2}$ & $\mathrm{CaO}$ & $\mathrm{Fe}_{2} \mathrm{O}_{3}$ & $\mathrm{Al}_{2} \mathrm{O}_{3}$ & $\mathrm{~K}_{2} \mathrm{O}$ & Others \\
\hline 35.3 & 30.5 & 17.0 & 10.8 & 3.4 & 3.0 \\
\hline
\end{tabular}

\subsection{Batch leaching test}

Shaking and non-shaking batch leaching tests with temperature control were carried out to assess the As leaching from the shale rock under different temperatures and contact time, using a single water to soil ratio of $10 \mathrm{~L} / \mathrm{kg}$ (i.e. $50 \mathrm{~g}$ soil in $500 \mathrm{~mL}$ water). Temperatures of $5,20,30$ and $40{ }^{\circ} \mathrm{C}$; and contact time of $6,24,96,192$ and $360 \mathrm{~h}$ were considered in the experiments.

Shaking batch leaching test was carried out in nearly same way to the Japanese Notification No. 46. Here the distilled water was stored in a $1000 \mathrm{~mL}$ polypropylene bottle; and in the case of $30{ }^{\circ} \mathrm{C}$ and $40{ }^{\circ} \mathrm{C}$, a temperature controller and a rubber heater attached on the outside of the bottle was used to heat the water. Temperatures of 20, 30 and $40{ }^{\circ} \mathrm{C}$ were considered for the test. After the desired temperature was confirmed, the sample was gently poured into the water, and mixing done by horizontal shaking at $200 \mathrm{rpm}$ for up to $360 \mathrm{~h}$, as shown in Fig. 4. After the shaking step, the supernatant was centrifuged at $3000 \mathrm{rpm}$ for $30 \mathrm{~min}$, which helps in separating the solid particles from the solution.

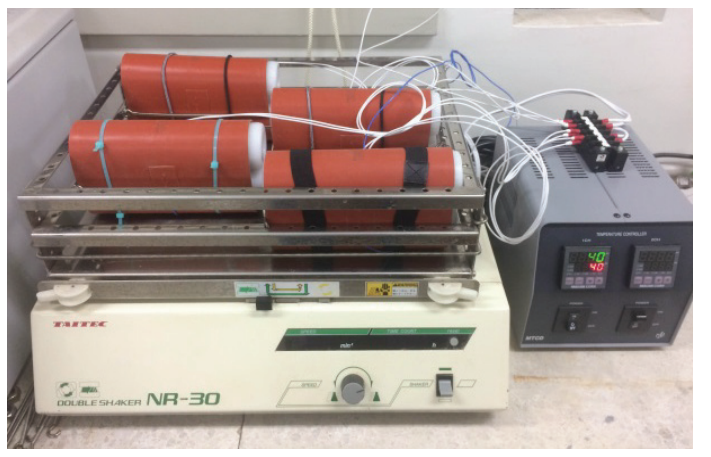

Fig. 4. Shaking step with temperature control system.

Non-shaking batch leaching test also suggests important findings for proper evaluation of metal leaching in practical situations because geomaterials in the ground or in geostructures should contact rainwater and/or groundwater without disturbance and agitation on-site. After adjusting the water temperature to the desired value $\left(5,20,30\right.$ or $\left.40{ }^{\circ} \mathrm{C}\right)$ using a refrigerator or rubber heater attached to the bottles, the sample was gently poured into water and the mixture stirred lightly, and then allowed to stand undisturbed for up to $360 \mathrm{~h}$, while maintaining the water temperature using the refrigerator or rubber heater. Supernatant was obtained in a similar way to the shaking test.

In both experiments, the supernatants were filtered using a membrane filter (Millex-HV, Millipore) with a particle size retention of $0.45 \mu \mathrm{m}$. And then the $\mathrm{pH}$, electrical conductivity (EC), and redox potential (Eh) were measured. Arsenic concentrations were measured by an atomic absorption spectrophotometer (AAS) (AA6800, Shimadzu). Concentrations of several cations (Al, $\mathrm{Ca}, \mathrm{Fe}, \mathrm{K}, \mathrm{Mg}$, and $\mathrm{Na}$ ) were measured by an inductively coupled plasma optical emission spectrometry (ICPOES) (ICP-OES 710, Agilent Technologies). 

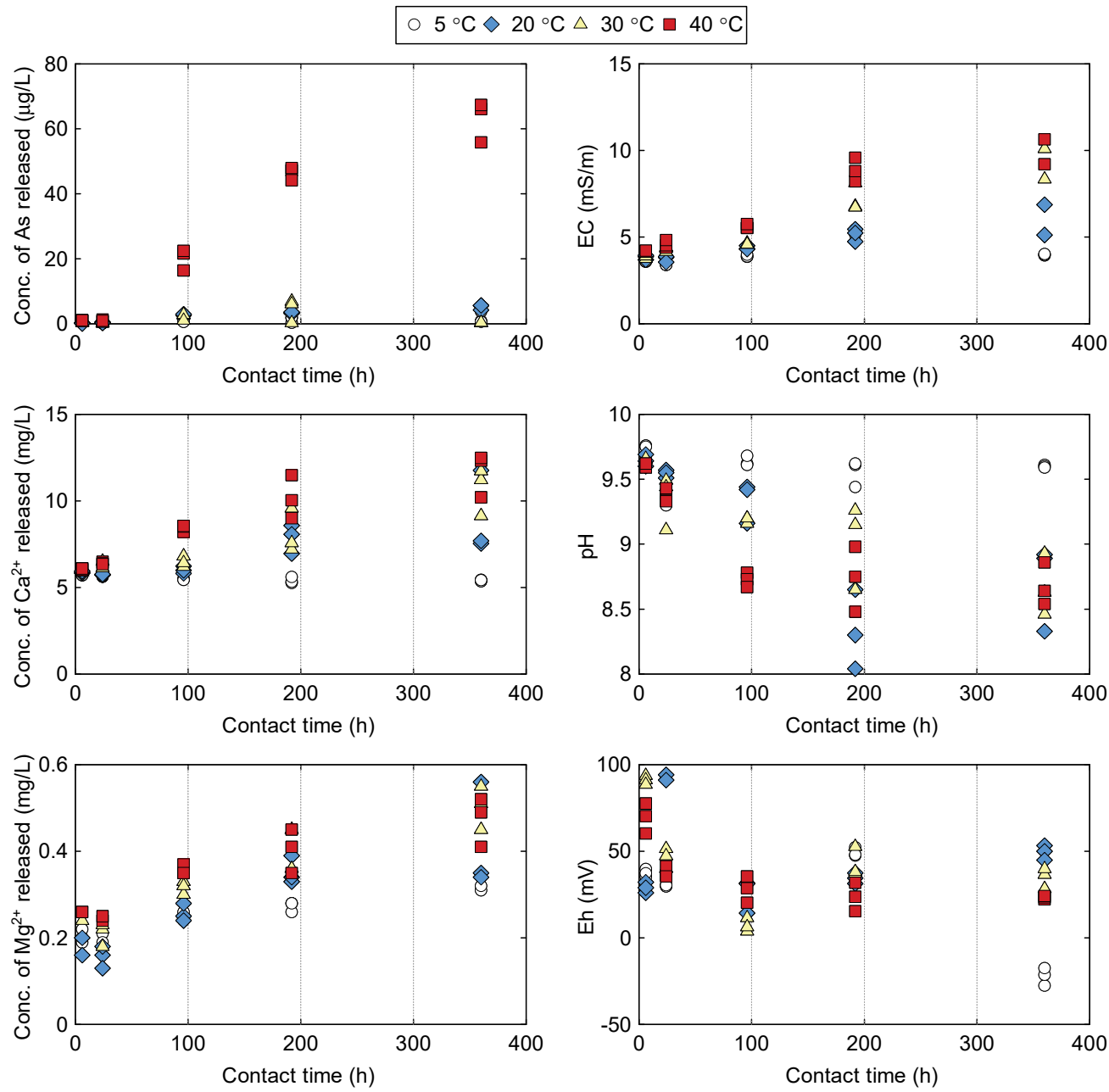

Fig. 5. Chemical indices and concentrations of leachate under non-shaking condition.

\section{Leaching behaviour under non- shaking condition}

Figure 5 shows the leachate chemistry under the nonshaking condition. Concentrations of As leached were found to increase with rise in temperatures and increase in the contact time; for temperatures below $30^{\circ} \mathrm{C}$, these values were not more than $0.004 \mathrm{mg} / \mathrm{L}$, which is a much lower value than the permissible limit of $0.01 \mathrm{mg} / \mathrm{L}$ in Japan. Concentrations of As in leachate were the highest at $40{ }^{\circ} \mathrm{C}$ with contact time of $360 \mathrm{~h}$, whereby ca. 0.06 $\mathrm{mg} / \mathrm{L}$ As was measured, which is 6 times above the permissible limit in Japan. Further, it was higher by at least 6 times, when compared to the leaching amounts at temperatures below $30^{\circ} \mathrm{C}$ for the same contact time.

Water-soluble elements like $\mathrm{K}^{+}, \mathrm{Ca}^{2+}$ and $\mathrm{Mg}^{2+}$ were also leached because of the interaction of soil and water. Overall, their leached amount was found to increase with rise in temperatures and increase in the contact time, which was similar to the leaching trend of As. Further, compared to the concentrations of other cations leached (e.g. $\mathrm{Mg}, \mathrm{K}$, etc), those of $\mathrm{Ca}^{2+}$ were highest with values of $5 \mathrm{mg} / \mathrm{L}$ or higher, for all the temperatures and contact time considered. At $40{ }^{\circ} \mathrm{C}$, ca. $10 \mathrm{mg} / \mathrm{L} \mathrm{Ca}^{2+}$ was leached which is 2 times compared to its leached amount at $5{ }^{\circ} \mathrm{C}$, where it was ca. $5 \mathrm{mg} / \mathrm{L}$. Although the $\mathrm{Ca}^{2+}$ is associated with concentration of hydroxides and carbonates whose solubility has a negative correlation with temperature [12]; it was noted that the leached amount of $\mathrm{Ca}^{2+}$ increases with rise in temperature, which suggests that the leaching of this cation is affected by both the quantity of Ca-related chemicals in the soil as well as the water temperature.

The leachate was found to be alkaline with $\mathrm{pH} 8-10$ which was attributed to the strong $\mathrm{pH}$ buffering effect of calcite mineral found in the shale rock; carbonate dissolution and precipitation will occur, and the presence of free carbonates is responsible for the alkaline leachate [13]. Further, higher leachate $\mathrm{pH}$ was measured at lower temperature and shorter contact time. In terms of Eh, in most cases, the soil leachates were under oxidising conditions, where $\mathrm{Eh}=0-100 \mathrm{mV}$. Similar to the trend of $\mathrm{pH}$, Eh decreased with more contact time.

Chemical forms of many dissolved compounds are influenced by the $\mathrm{pH}$ and Eh of the water. Dissolved As under oxidising conditions between $\mathrm{pH} 7-11$ is generally present as the negatively charged $\mathrm{HAsO}_{4}{ }^{2-}$ oxyanion, which has a low mobility and toxicity [14]. 

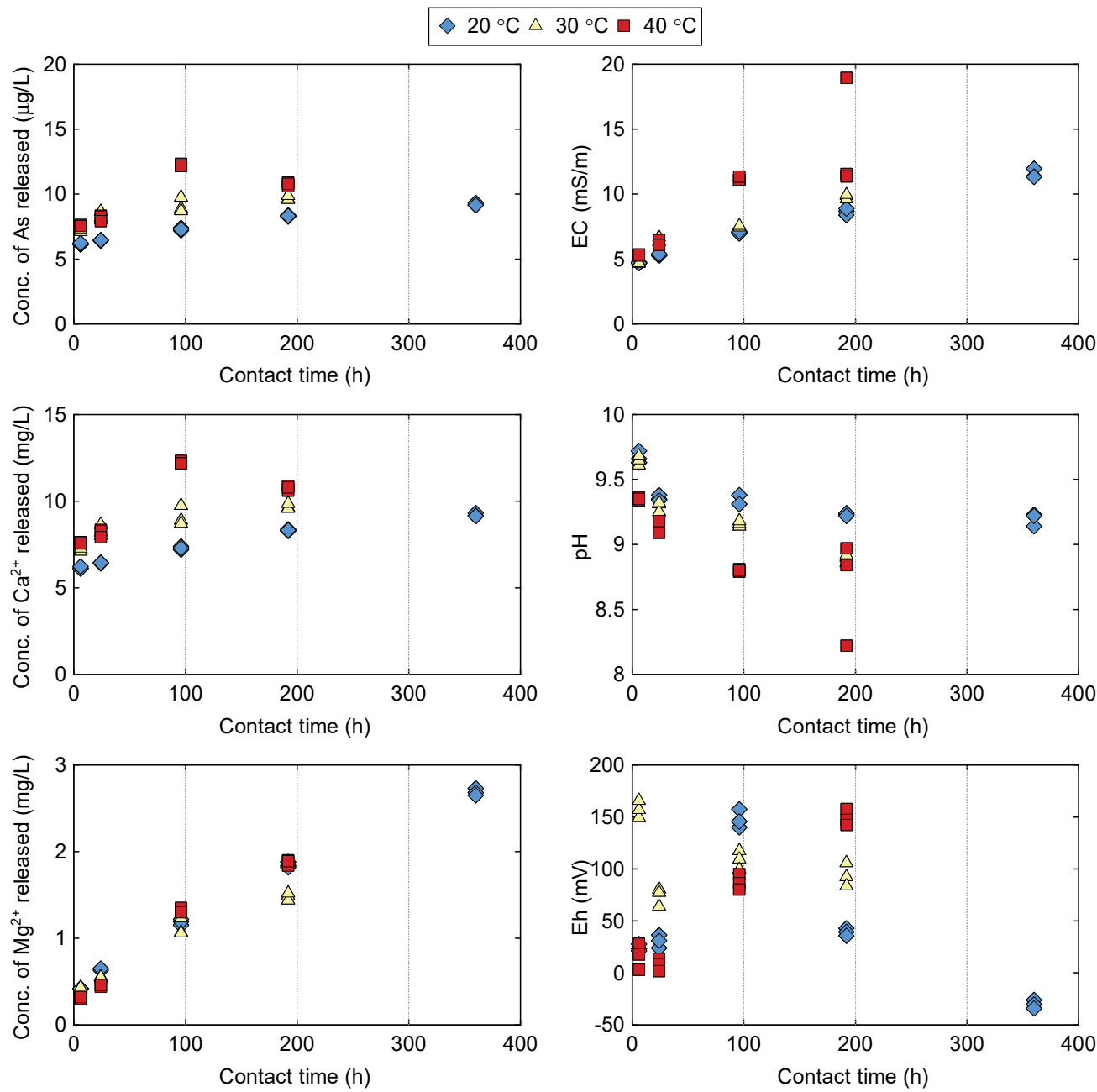

Fig. 6. Chemical indices and concentrations of leachate under shaking condition.

\section{Leaching behaviour under shaking condition}

Similar to the non-shaking condition, Fig. 6 shows that under shaking condition, the concentration of As leached generally increased with rise in temperature and a longer contact time. For temperatures above $30{ }^{\circ} \mathrm{C}$ and contact time longer than or equal to $24 \mathrm{~h}$, these values exceeded the permissible limit. In shaking condition, the highest concentration of ca. $0.02 \mathrm{mg} / \mathrm{L}$ As was measured for water temperature of $40{ }^{\circ} \mathrm{C}$ and contact time of $96 \mathrm{~h}$, which is 2 times higher than the permissible limit. Further, when comparing the results of shaking and nonshaking condition, under shaking condition the values were slightly higher for contact time less than or equal to $24 \mathrm{~h}$, and much lower for contact time longer than $24 \mathrm{~h}$.

Leaching trends of $\mathrm{Ca}^{2+}$ and $\mathrm{Mg}^{2+}$ under the shaking condition was also similar to those observed under nonshaking condition. From comparison of their leaching values under shaking and non-shaking condition, it was found that there were no significant differences in the concentration of $\mathrm{Ca}^{2+}$ for both conditions, but more $\mathrm{Mg}^{2+}$ were leached under the shaking condition. These results suggest that leaching of more cations $\left(\mathrm{Ca}^{2+}+\mathrm{Mg}^{2+}\right)$ under the shaking condition compared to non-shaking condition, may have contributed to lower concentrations of As.

Trends of EC, Eh and $\mathrm{pH}$ under the shaking condition were found to be also similar to those under the non-shaking condition. Further, in most cases, Eh-pH characteristics of the leachate was found to favour the occurrence of $\mathrm{As}$ as the $\mathrm{HAsO}_{4}{ }^{2-}$ oxyanion.

\section{Conclusions}

This study aimed at clarifying the effects of temperature changes, which can occur due to solar radiation and thermal-active geosystems, on the leaching of As from shale rock contaminated with geogenic As. From the findings of the shaking and non-shaking batch leaching test, these conclusions were reached:

1) Generally, for temperatures lower than or equal to $20^{\circ} \mathrm{C}$, the leaching concentrations of As were not more than $0.004 \mathrm{mg} / \mathrm{L}$, which is a much lower value than the permissible limit of $0.01 \mathrm{mg} / \mathrm{L}$ regulated under the SCCL. 
2) Higher temperatures of above $30{ }^{\circ} \mathrm{C}$ and/or contact time longer than $24 \mathrm{~h}$ will increase the leaching concentrations of As; and the values can increase by 2 times or more when the temperature is raised from 20 to $40{ }^{\circ} \mathrm{C}$ and above, and a longer contact time of $96 \mathrm{~h}$ or more.

3) Comparing shaking and non-shaking condition, the leaching concentrations of As will generally be higher under the non-shaking condition, for contact time longer than $24 \mathrm{~h}$. Under non-shaking condition, the concentrations of As in leachate were the highest at $40{ }^{\circ} \mathrm{C}$ with contact time of $360 \mathrm{~h}$, whereby ca. $0.06 \mathrm{mg} / \mathrm{L}$ As was measured, which is 6 times above the permissible limit in Japan.

\section{References}

1. T. Katsumi, T. Inui, M. Kamon, "Sustainable geotechnics for reuse of by-products" Proc. of the 6th International Congress on Environmental Geotechnics, M. Datta, R.K. Srivastava, G.V. Ramana, and J.T. Shahu (eds.), pp.302-317 (2010)

2. T. Inui, M. Katayama, T. Katsumi, A. Takai, M. Kamon, "Evaluating the Long-Term Leaching Characteristics of Heavy Metals in Excavated Rocks" J. Soc. Mater. Sci., 63, 1 73-78 (2014) (in Japanese)

3. U. Kalbe, W. Berger, J. Eckardt, F.-G. Simon, "Evaluation of Leaching and Extraction Procedures for Soil and Waste" J. Waste Manag., 28, 6, 1027 $1038(2008)$

4. G. Florides, S. Kalogirou, "Annual ground temperature measurements at various depths" Proc. CLIMA 2005 (2005)

5. M.R. Alam, M.F.M. Zain, A.B.M.A. Kaish, M. Jamil, "Underground soil and thermal conductivity materials based heat reduction for energy-efficient building in tropical environment" Indoor Built Environ., 24, 2, 185-200 (2015)
6. S. Tamoto, Y. Ito, K. Okazaki, "The leaching characteristics of arsenic from rocks (Part 3)" Proc. 43rd JGS National Conference, 2079-2080 (2008) (in Japanese)

7. T. Saito, S. Hamamoto, T. Ueki, S. Ohkubo, P. Moldrup, K. Kawamoto, T. Komatsu, "Temperature change affected groundwater quality in a confined marine aquifer during long-term heating and cooling" Water Research, 94, 120-127 (2016)

8. T. Başer, Y. Dong, A.M. Moradi, N. Lu, K. Smits, S. Ge, D. Tartakovsky, J.S. McCartney, "Role of water vapor diffusion and nonequilibrium phase change in geothermal energy storage systems in the vadose zone" J. Geotech. Geoenviron. Eng., 144, 7, 04018038 (2018)

9. B. Wang, A. Bouazza, R.M. Singh, C. Haberfield, D. Barry-Macaulay, S. Baycan, "Posttemperature Effects on Shaft Capacity of a Full-Scale Geothermal Energy Pile" J. Geotech. Geoenviron. Eng., 141, 4, 04014125-1-12 (2015)

10. A. Takai, T. Inui, T. Katsumi, "Effects of contact time and temperature on arsenic leaching from excavated mudstone" Proc. 7th China-Japan Geotechnical Symposium, 289-295 (2018)

11. D. Panagiotaras, D. Nikolopoulos, "Arsenic Occurrence and Fate in the Environment; A Geochemical Perspective" J. Earth Sci. Clim. Change, 6, 1-9 (2015)

12. D. Hunter, "Lime-Induced Heave in Sulfate-Bearing Clay Soils" J. Geotech. Eng. 114, 2, 150-167 (1988)

13. M.B. McBride, Environmental Chemistry of Soils (1994)

14. J.V. Bothe, P.W. Brown, "The Stabilities of Calcium Arsenates at 23+/-1 Degrees C" J. Hazard. Mater., 69, 2, 197-207 (1999) 